\title{
The Effect of Luting Agents and Ceramic Thickness on the Color Variation of Different Ceramics against a Chromatic Background
}

\author{
Gloria Beatriz de Azevedo Cubasa \\ Guilherme Brião Camachob \\ Flávio Fernando Demarcob \\ Tatiana Pereira-Cencib
}

\section{ABSTRACT}

Objectives: The aim of this study was to assess the influence of various ceramic thicknesses and luting agents on color variation in five ceramic systems.

Methods: Fifteen disc-shaped ceramic specimens (11 mm diameter; shade A3) were fabricated with each of the six veneering ceramics tested, with 1, 1.5, or $2 \mathrm{~mm}$ thickness ( $\mathrm{n}=5$ ). Resin composite discs (Z-250, shade C4) were used as bases to simulate a chromatic background. The cementation of the veneers was carried out with an opaque resin-based cement (Enforce, shade C4), a resin-based cement (Enforce, shade A3), or without cement (C4, control group). Color differences ( $\triangle E^{*}$ ) were determined using a colorimeter. Three-way ANOVA was used to analyze the data, followed by a Tukey post-hoc test $(\alpha=.05)$.

Results: The $L * a * b *$ values of the ceramic systems were affected by both the luting agent and the ceramic thickness $(P<.05)$. In general, there was no difference between the control group and the group using the resin-based cement. The use of an opaque luting agent resulted in an increase of the color coordinates $a^{*}, b^{*}, L^{*}$, producing differences in $\Delta \mathrm{E}^{*}$ values for all ceramics tested, regardless of the thickness $(\mathrm{P}<.05)$. For the $2-\mathrm{mm}$ thick veneers, higher values in the color parameters were obtained for all ceramics and were independent of the luting agent used.

Conclusions: The association of 2-mm thickness with opaque cement presented the strongest masking ability of a dark colored background when compared to a non-opaque luting agent and the other thicknesses tested. (Eur J Dent 2011;5:245-252)

Key words: Ceramics; Luting agents; Thickness; Color.

\footnotetext{
- a Graduate student, Department of Restorative Dentistry, School of Dentistry, Federal University of Pelotas, Brazil. b Associate Professor, Department of Restorative Dentistry, School of Dentistry, Federal University of Pelotas, Brazil.

- Corresponding author: Tatiana Pereira-Cenci School of Dentistry, Federal University of Pelotas Rua Gonçalves Chaves, 457, $2^{\text {nd }}$ floor

Pelotas - RS - Brazil 96015560

Phone/Fax: +55 5332226690

E-mail: tatiana.cencidufpel.tche.br
}

\section{INTRODUCTION}

The search for an optimal anterior tooth with ceramic veneers has intensified in recent decades as a result of patients' expectations for achieving aesthetic results that include an individualized color-matching between the ceramic and adjacent natural dentition. ${ }^{1-3}$ Although problems such as marginal leakage, secondary caries, tooth sensitivity, and displacement or fracture have be- 
come less frequent, ${ }^{4-6}$ the final color matching of ceramic veneers to adjacent natural dentition remains problematic. ${ }^{7}$ Replicating the appearance of tooth structure requires careful control of the form, surface texture, translucency, and color of the restoration. ${ }^{8}$

Obtaining the desired final color in a ceramic restoration is complex and constitutes a challenge because factors such as the degree of opalescence, translucency, fluorescence, surface texture and shape properties, ceramic brand $d^{2,8,9}$ and batches, ${ }^{9}$ number of ceramic firings, and the condensation technique ${ }^{10-12}$ may also affect the final shade of the ceramic. In addition, the final color may be affected by the combination of ceramic color and thickness, together with the luting agent and the color of the underlying dental structure. . $^{3,4,10,12,14-16}$ As a result, in some cases, the ceramic color chosen may not correspond with the exact color of the tooth.

When evaluating the final aesthetic quality of ceramic veneers, recognizing the extent to which the restoration masks color variations that may be present in the underlying dental structure is mandatory in composing a harmonious effect with the adjacent natural teeth and reproducing optical properties similar to those present in the dental structure. ${ }^{12}$ As a consequence, the overall color produced should not be separately evaluated. ${ }^{17}$

Color is characterized as a sensation obtained through proprioceptive mechanisms, and standardized colorimetric techniques have been developed to characterize colors in terms of numeric values. ${ }^{8}$ The CIE L*a*b system of colors was created based on the primary colors ${ }^{18}$ to eliminate inconsistencies inherent in color perception and specification among varied observers. ${ }^{8}$ Several color studies have evaluated isolated factors that may cause color alterations in ceramic material, such as repeated firings, ceramic thickness, glaz-

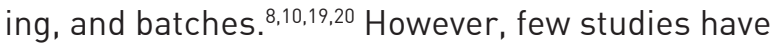
evaluated the interaction of factors that comprise the ceramic restoration, especially considering that the restoration will function as one body lunderlying dental structure, luting agent, and ceramic thickness) resulting in the final aesthetic aspect. ${ }^{17}$ Taking this into account, a comprehensive determination of thickness, luting agent, and background color altogether will optimize color selection. $4,10,16,17$
The aim of this study was to evaluate the effect of luting agents and ceramic thicknesses cemented on a chromatic background on the final color of the ceramic. The null hypothesis tested was that there would be no difference in the ceramic color when the thickness of the ceramic and color of the luting agent were varied.

\section{MATERIALS AND METHODS}

For this study, six ceramics were used: Vitadur-Alpha (Vita Zanhfabrik, Bad Sackingen, Germany); Noritake Super Porcelain EX-3 (Noritake Kizai Co., Ltd., NG, Japan); Vision-Esthetic (Servo dental, Cologne, Germany), IPS Classic (Ivoclar Vivadent, Bendererstrasse Schaan, Liechtenstein), All Ceram (Ducera, Rosbach, Germany), and Vintage Halo (Shofu, Shangai, Japan). Fifteen ceramic discs were manufactured from each ceramic and divided into 3 groups $(n=5)$ according to the thickness (1, 1.5, or $2 \mathrm{~mm})$, using an adjustable standardized metallic matrix (11 $\mathrm{mm}$ diameter). The discs were fired, followed by glazing (Titan 99, EDG Equipments Ltd, São Paulo, Brazil), according to the manufacturers' recommendations. After firing, the disks were ground on the veneer side using 220-, 400-, and 600-grit sandpaper under water cooling to standardize the surfaces, followed by polishing with silicone points (Exa Cerapol, Eve, Pforzheim, Germanyl.

To simulate the color of a dark underlying dental structure, background discs, color $\mathrm{C} 4$, with 30 $\mathrm{mm}$ diameter, were made using resin composite (Filtek Z-250 ${ }^{\circledR}, 3$ M ESPE, St Paul, MN, USA). The ceramic discs with varying thicknesses were seated on the dark background of the resin composite with either resinous opaque cement (C4OP, Enforce, DENTSPLY ${ }^{\circledR}$, São Paulo, Brazil) or resinous cement (C4A3; Enforce, DENTSPLY ${ }^{\circledR}$ ), according to manufacturers' instructions. Another group, without cement, served as a control. The luting agents were applied and pressed onto the inner (nonglazed) surface between the ceramic and a glass slide using a micrometer (Mitutoyo, Neuss, Germanyl, producing a cement thickness of $0.2 \mathrm{~mm}$.

\section{Color evaluation}

The evaluation of the color parameters was determined using the CIE Lab system of colors using a colorimeter (Color-Guide ${ }^{\circledR}$, BYK-Gardner, Columbia, MD, USA). In the CIE Lab system, the 
place of a color in the space is defined in terms of 3 coordinates: $L^{*}, a^{*}$, and $b^{*}$. The $L^{*}$ coordinate is a measure of the lightness-darkness of the specimen, on a numerical scale from 0 (black) to 100 (white). The measure of the total difference of color between 2 objects is described by $\Delta \mathrm{E}$. Color differences above 3.7 units are visually detected. The formula used to calculate the $\Delta \mathrm{E}$ was: $\Delta \mathrm{E}_{\mathrm{ab}}{ }^{*}=[(\mathrm{L} \mathrm{L}$ $\left.*)^{2}+(\Delta \mathrm{a} *)^{2}+\left(\Delta \mathrm{b}^{*}\right)^{2}\right]^{1 / 2}$. The $\Delta \mathrm{E}$ values were graded as follows: $\Delta \mathrm{E}<1=$ not appreciable, $\Delta \mathrm{E}<2$ = clinically acceptable, $\Delta \mathrm{E}>2$ = clinically unacceptable, $\Delta \mathrm{E}>3.7$ = clinically unacceptable with very poor match. ${ }^{17,21,22}$ The $L^{*}{ }^{*}{ }^{*} b^{*}$ color notation for each specimen was measured 3 times consecutively, and an average was calculated to give the initial color of all substrata. $\mathrm{A} \Delta \mathrm{E}>3.7$ was considered to be clinically unacceptable.

\section{Statistical analysis}

Statistical analyses were performed employing a significance level fixed at $5 \%$. The null hypotheses assumed no differences among ceramic thickness and luting agents. Data that violated the assumptions of equality of variances and normal distribution of errors were transformed and analyzed by three-way ANOVA, followed by the Tukey test. The influence of the different ceramic thicknesses, luting agents, and their interaction on the final color of the ceramic veneers were analyzed.

\section{RESULTS}

Three-way ANOVA showed that the mean values of $L^{*}, a^{*}$, and $b^{*}$ were often significantly influenced by the ceramic brand, luting agent, thickness, and interaction terms of the 3 variables (Table 1, $\mathrm{P}<.001$ ). For all the ceramics tested, in general, the thickness of 1.5 and $2 \mathrm{~mm}$ resulted in higher $a^{*}, b^{*}$ and $L^{*}$ values when compared with the $1 \mathrm{~mm}$ thickness, regardless of the luting agent applied (Figures 1, 2 and 3). The use of an opaque

\begin{tabular}{lccc}
\hline \multicolumn{4}{c}{ Table 1. P-values of 3-way ANOVA in accordance to with color parameters. } \\
\hline Source & \multicolumn{1}{c}{ * $^{*}$} & $\mathrm{a}^{*}$ & b* $^{*}$ \\
\hline Ceramic & $<0.0001$ & $<0.0001$ & $<0.0001$ \\
\hline Luting agent & $<0.0001$ & $<0.0001$ & $<0.0001$ \\
\hline Thickness & $<0.0001$ & $<0.0001$ & $<0.0001$ \\
\hline Ceramic $x$ luting agent & $<0.0001$ & $<0.0001$ & $<0.0001$ \\
\hline Ceramic $x$ thickness & $<0.0001$ & $<0.0001$ & $<0.0001$ \\
\hline Luting agent $x$ thickness & $<0.0001$ & $<0.0001$ & $<0.0001$ \\
\hline Ceramic $x$ luting agent $x$ thickness & 0.8447 & 0.0878 & 0.0424 \\
\hline
\end{tabular}

July 2011 - Vol.5 cement resulted in higher $a^{*}, b^{*}$, and L* values for all thicknesses and ceramics tested.

Lower a* values were obtained in the $1 \mathrm{~mm}$ thickness ceramics without the opaque, while the use of the opaque cement with 1.5 and $2 \mathrm{~mm}$ thicknesses resulted in higher $a^{*}$ values $(P<.05)$. No difference occurred between the 1.5 and $2 \mathrm{~mm}$ thickness when the opaque cement was applied (Figure 1).

Following the same trend as the $a^{*}$ values, higher $b^{*}$ values $(P<.001)$ were obtained when the opaque was applied, except for the ceramics Vintage Halo and Vision Esthetic, which did not result in differences in $b^{*}$ values $(P>.05)$. The use of 2 $\mathrm{mm}$ ceramic with an opaque luting agent resulted in the higher $b^{*}$ values (Figure 2). For all ceramics tested, the use of an opaque cement resulted in higher $L^{*}$ values when compared to the other cements $(P<.001)$.

A significant increase in $\mathrm{L}^{*}$ with $2 \mathrm{~mm}$ thickness was obtained for all ceramics tested. When the opaque cement was associated with ceramics with $2 \mathrm{~mm}$ thickness, the highest $L^{*}$ values could be observed $(P<.001$, Figure 3$)$. For the $\Delta E^{*}$ values, the results showed that the use of the opaque cement resulted in higher $\Delta \mathrm{E}^{*}(\mathrm{P}<.001)$. In addition, the use of the $2 \mathrm{~mm}$ thickness ceramic leaded to the higher $\Delta E^{*}$ value $(P<.001)$, except for Vision Esthetic, which presented the same $\Delta \mathrm{E}^{*}$ value when comparing 1 and $2 \mathrm{~mm}$ thickness. The highest $\Delta \mathrm{E}^{*}$ values were obtained with the combination of a ceramic thickness of $2 \mathrm{~mm}$ with a cement containing opaque (Table 2).

\section{DISCUSSION}

This study simulated a clinical situation in which veneers are not individual layers of ceramic, but rather comprise a complete unit, with a background simulating the dentin, the luting agents, and the ceramic layers. ${ }^{17}$ The influence of the type of luting agent used and the different ceramic thicknesses, which can vary clinically, were evaluated to verify their influence on color parameters.4,10,20,23,24 All-ceramic restorations luted to the tooth substrate are influenced by the shade and thickness that contribute to the final appearance of the ceramic restorations. ${ }^{17,25}$ The use of an opaque luting agent resulted in higher values for all color parameters evaluated when compared to 
the non-opaque cement. This resulted in reddish $\left(a^{*}\right)$, yellowish $\left(b^{*}\right)$, and lighter $\left(L^{*}\right)$ ceramic specimens, with increased $\Delta \mathrm{E}^{*}$ values for all ceramic tested (Table 2). To evaluate color in all ceramic veneers, it is important to consider the role of the luting agent in masking the background shade. ${ }^{25}$ In a general way, there was no difference in the color parameters when comparing non-opaque and the control group (without cement). From the present study results, it appears that the use of a luting agent without opaque qualities did not bring any benefit to mask a darkened background. Availability of different cement shades allows small aesthetic corrections, which may be instrumentally detectable, but are not clinically relevant. ${ }^{14}$ Additionally, the use of an opaque luting agent was associated with increased values of the $L^{*}$ color parameters, resulting in lighter ceramic

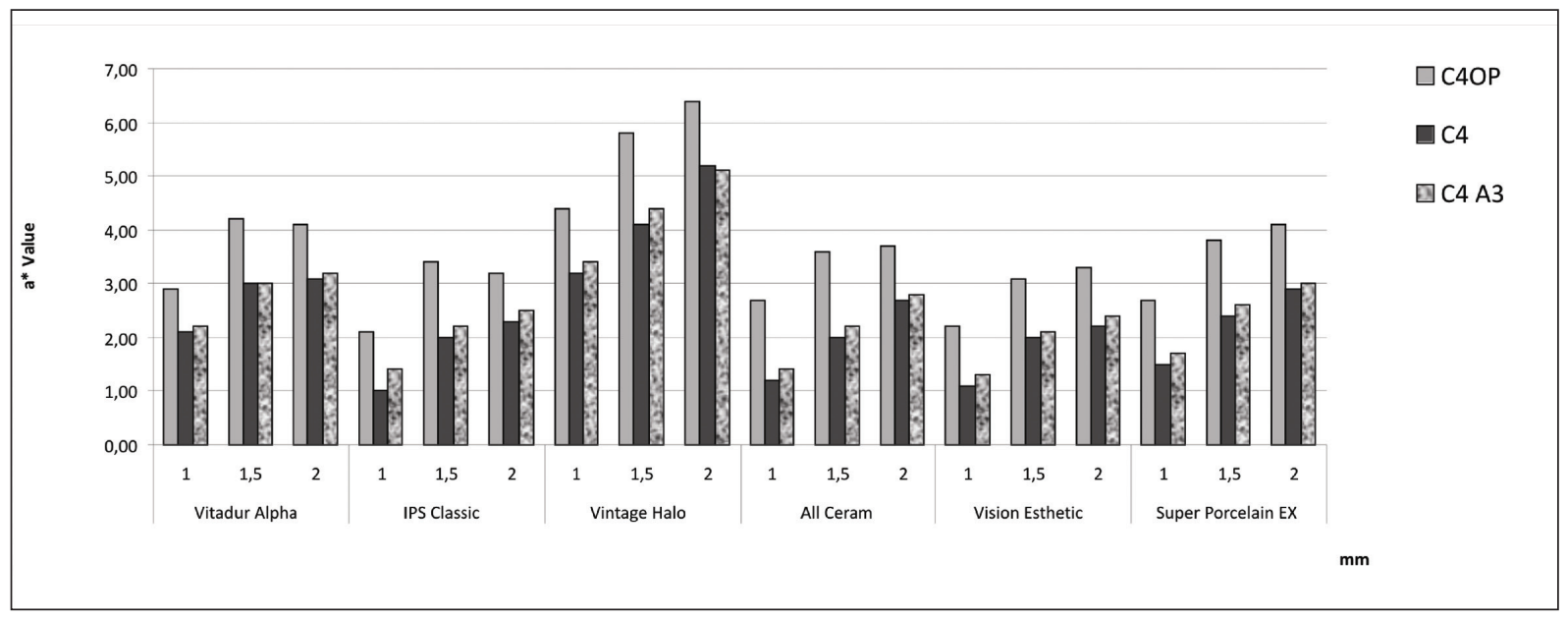

Figure 1. $a^{*}$ values.

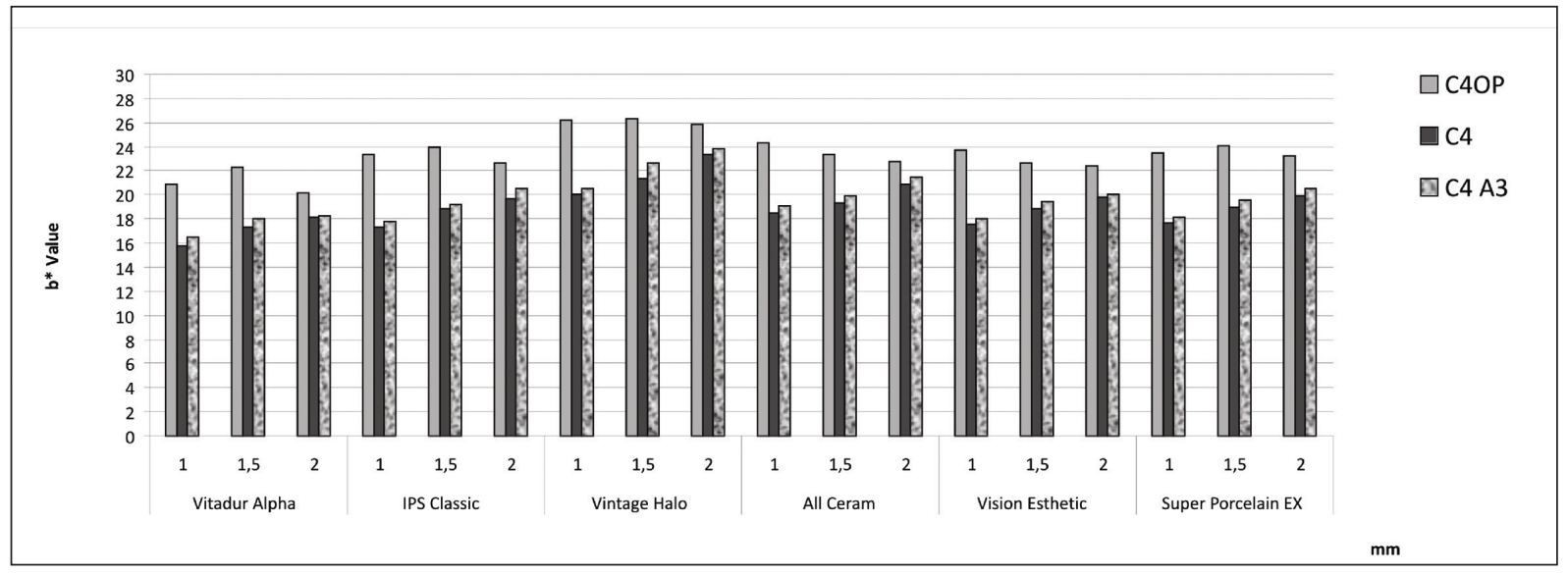

Figure 2. $b^{*}$ values.

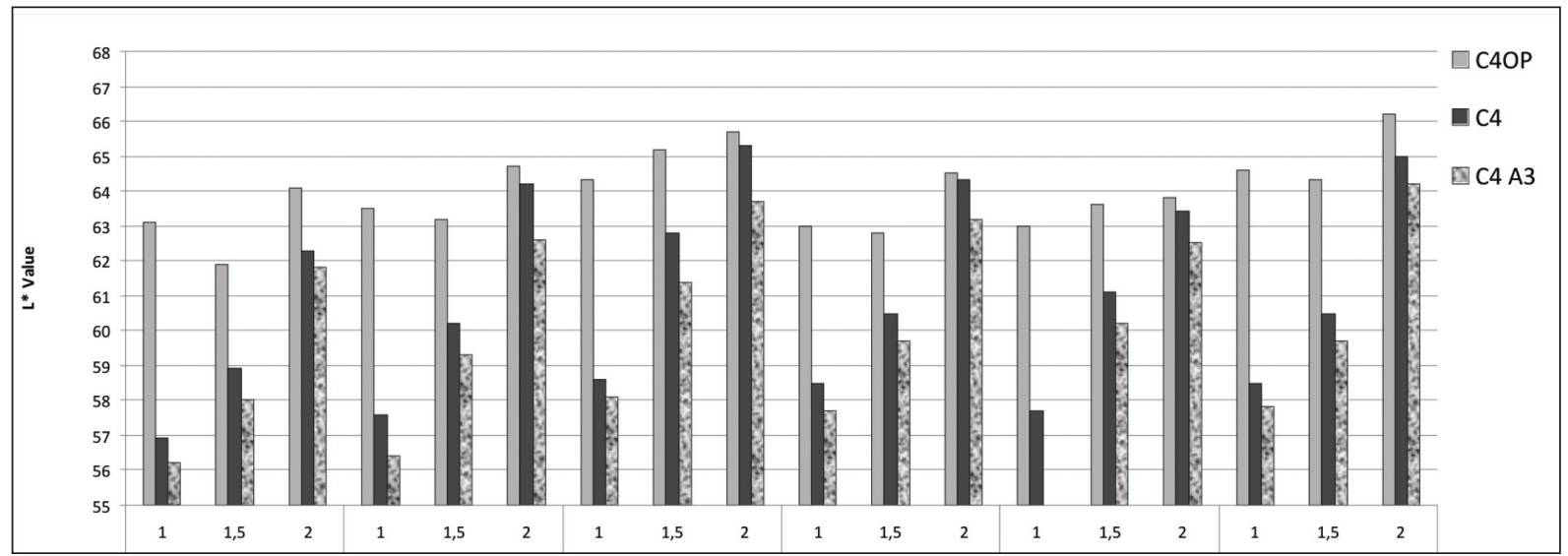

Figure 3. L* values. 
specimens for all the ceramic used regardless of the ceramic thickness (Figure 3). This finding may suggest a possible resource for improving the esthetics of darkened teeth.

In this study, varying thicknesses of the ceramics influenced the color parameters evaluated, overall presenting higher $a^{*}, b^{*}, L^{*}$ values when thicker veneers were used, regardless of the luting agent, therefore resulting in $\Delta \mathrm{E}^{*}$ values above the 3.7 units that are visually detected (Figures 1, 2 and 3). Apparently, increasing dental ceramic thickness results in increased $b^{*}$ values. ${ }^{26}$ In this study, ceramics with $2 \mathrm{~mm}$ thickness had an increased $L^{*}$ parameter resulting in lighter ceramic specimens, promoting higher masking of the darkened background. The increase of 0.4 $\mathrm{mm}$ in specimens with $1 \mathrm{~mm}$ thickness has been shown to have no influence on the color properties of different ceramics, although the increase may be clinically relevant. ${ }^{17}$ Also, the final esthetic result of IPS-Empress all-ceramic/glass-ceramic restorations was not affected by the presence of varying substrates with different colors when the thickness was more than $2 \mathrm{~mm}^{14}$

The six ceramics tested presented initial burning temperatures varying from 400 to $600^{\circ} \mathrm{C}$. Sintering temperatures also varied from 770 to $950^{\circ} \mathrm{C}$. The importance of these temperatures is that varying temperatures (i.e., different from those recommended by the manufacturers) leads to col- or variation. ${ }^{27}$ The composition of the conventional (feldspathic) ceramics tested as supported by the manufacturer is (mol\%) 59.5-70 $\mathrm{SiO}_{2}, 11-18 \mathrm{Al}_{2} \mathrm{O}_{3}$, 3-8 $\mathrm{Na}_{2} \mathrm{O}, 7-14 \mathrm{~K}_{2} \mathrm{O}$, and a smaller amount of other oxides and pigments, depending on the ceramic manufacturer. The differences among ceramics may be important when choosing specific ceramic systems, as materials have different particle sizes, packing volumes, and refractive indices. ${ }^{28}$ For instance, if we compared a densely sintered alumina, such as Procera, with a conventional ceramic, such as Vitadur Alpha, the first possesses significantly better contrast ratios and masking ability, as a high percentage of alumina intercepts incident light more efficiently than the feldspathic ceramic. ${ }^{29}$ Laboratory experience and expertise should be also taken into account ${ }^{30}$ when selecting a specific ceramic amongst the available systems.

The interaction of ceramic thickness and type of luting agent was also significant in this study $(P<$.001), increasing all color parameters. The highest $a^{*}, b^{*}, L^{*}$, and $\Delta E^{*}$ values resulted from the association of an opaque luting agent with a $2 \mathrm{~mm}$ thickness veneer (Figures 1 and 2; Table 2). Ceramic specimens with $1 \mathrm{~mm}$ thickness with the opaque luting agent presented increased color values $\left(a^{*}, b^{*}, L^{*}\right)$ when compared to the resin based and controls with the same thickness. However, the values of all color parameters, especially $L^{*}$, were smaller when compared to the

Table 2. $\Delta \mathrm{E}^{*}$ for the tested ceramics. Values are mean (standard deviation).

\begin{tabular}{|c|c|c|c|c|}
\hline \multirow{2}{*}{ Product Name } & \multirow{2}{*}{$\begin{array}{l}\text { Ceramic Thickness } \\
\qquad(\mathrm{mm}]\end{array}$} & \multicolumn{3}{|c|}{$\Delta \mathrm{E}^{*}$} \\
\hline & & C40P & C4 & C4A3 \\
\hline \multirow{3}{*}{ Vitadur Alpha } & 1 & $13.7(1.8)$ & $3.5(1.1)$ & $4.2(0.8)$ \\
\hline & 1.5 & $18.1(1.9)$ & $0.3(0.1)$ & $0.8(0.4)$ \\
\hline & 2 & $18.7(2.5)$ & $6.2(0.9)$ & $4.9(0.6)$ \\
\hline \multirow{3}{*}{ Vintage Halo } & 1 & $16.3(1.0)$ & $4.1(0.5)$ & $4.3(0.9)$ \\
\hline & 1.5 & $22.2(7.6)$ & $3.0(2.0)$ & $1.3(1.3)$ \\
\hline & 2 & $23.7(1.7)$ & $13.1(0.9)$ & $7.7(0.5)$ \\
\hline \multirow{3}{*}{ Vision Esthetic } & 1 & $15.6(0.7)$ & $3.9(0.3)$ & $5.1(0.6)$ \\
\hline & 1.5 & $15.9(1.6)$ & $0.9(0.4)$ & $0.4(0.1)$ \\
\hline & 2 & $14.4(1.0)$ & $7.5(1.1)$ & $4.2(0.2)$ \\
\hline \multirow{3}{*}{ IPS Classic } & 1 & $17.0(1.9)$ & $4.4(1.1)$ & $7.4(1.5)$ \\
\hline & 1.5 & $20.4(3.2)$ & $0.2(0.1)$ & $0.8(0.4)$ \\
\hline & 2 & $20.3(1.7)$ & $9.2(1.0)$ & $5.4(0.8)$ \\
\hline \multirow{3}{*}{ All Ceram } & 1 & $13.5(0.7)$ & $3.1(0.4)$ & $4.3(0.6)$ \\
\hline & 1.5 & $10.6(0.9)$ & $0.2(0.1)$ & $0.5(0.2)$ \\
\hline & 2 & $14.2(0.5)$ & $8.0(0.7)$ & $5.5(0.2)$ \\
\hline
\end{tabular}

July 2011 - Vol.5 
other groups tested, when thicker veneers 11.5 and $2 \mathrm{~mm}$ ) were used. This may represent a diminished capacity to mask the background color; therefore, the aesthetic result may not be satisfactory. These results corroborate another study, which found that if the ceramic thickness is less than $1 \mathrm{~mm}$, a color match of the abutment is required to ensure an acceptable aesthetic result. ${ }^{14}$ When ceramic thickness decreases to $1.5 \mathrm{~mm}$, it is advisable to take the substrate aspects into consideration. ${ }^{14}$ Although deeper preparation for ceramic veneers presents some disadvantages related to the adhesion of the veneer to the underlying dental structure and more sound tissue removal lthe increased amount of tooth reduction thereby necessary can jeopardize pulpal health), it also promotes enhanced masking of the darkened tooth. ${ }^{29,31}$

The choice of using a chromatic background was intended to simulate a typical clinical condition in which a dark underlying dental structure is present and a ceramic veneer restoration is planned. 4,31 The background color of an aesthetic restoration is more or less chromatic, and the thickness of the material can vary. ${ }^{4,16}$ The use of black and white backgrounds has been reported in several studies in order to standardize the collection of the color data, but this methodology can influence the final color of the ceramic. ${ }^{17}$ Clinically, a composite restoration with a white cement base may appear lighter, more reddish, and more saturated than that with a dark background. ${ }^{16}$ This effect becomes smaller as the thickness of the sample increases. ${ }^{16}$ When increasing resin thickness, the resin may appear darker and less chromatic with a white background, and lighter and more chromatic with a black background. ${ }^{32}$ Therefore, a sample may be more or less chromatic depending on its thickness and whether the background is white or black. ${ }^{32}$

A limitation of this study is that only one ceramic shade (A3) was tested; other ceramic shades may perform differently. ${ }^{17}$ Ceramics with higher chromatic shades are more affected by changes in enamel-ceramic thickness than are those with lower chroma. ${ }^{23}$ Different shades of the same ceramic with the same thickness can present differences in light transmission, resulting in differences in optical performance and color parameters. ${ }^{24,26}$ In this study, only one luting agent thickness was used for standardization purposes. However, differences in cement thickness 10.1 or $0.2 \mathrm{~mm}$ ) may slightly affect the final result in ceramic veneers. ${ }^{14}$ Conversely, as this parameter can only be controlled by the operator to a certain extent, it may not be considered as a procedure for attaining correct color. ${ }^{14}$ Additionally, it is important to highlight that the masking ability of ceramic materials can be evaluated with a spectrophotometric instrument in terms of the opacity or contrast ratio. The contrast ratio $(\mathrm{CR}=\mathrm{Yb} /$ $Y w)$ is defined as the ratio of illuminance $(Y)$ of the test material when it is placed over a black background $(\mathrm{Yb})$ to the illuminance of the same material when it is placed over a white background $(Y w){ }^{33-35}$ Some colorimeters approximate with filters the light from a specific illuminant and the specific observation characteristics of the human observer. This color data is then valid only for that illuminant and observer. Significant advantages to spectrophotometric measurements include the ability to analyze the principal components of a series of spectra and the ability to convert spectrophotometric measures to various color measures. Also, a distinct advantage of the CIE Lab system of colors is the simplicity of calculating a color difference between two colors using the previously described formula. 17,21,22,35

Although in vitro studies simulate clinical reality and may be a clue as to how these restorations will perform clinically, randomized controlled trials are necessary to investigate the magnitude of color alterations and their differences under clinical conditions. Studies that analyze ceramic restorations as a unit composed of dental substratum, luting agent, and ceramic thickness could help in understanding the factors involved in producing the final color of a ceramic restoration. ${ }^{17}$ Such information would be useful for establishing a guideline for daily practice and could help to determine the need for tissue reduction associated with product selection, to increase the capacity of different ceramic systems in masking dental color substratum, and to assist in optimize shade selection.

\section{CONCLUSIONS}

Within the limitations of this study, it can be concluded that the thickness of a ceramic material can affect its translucency and color, there- 
fore presenting higher capacity for masking a dark substrate when fabricated with higher thickness. Knowledge of the color properties of ceramics enables the clinician to make appropriate choices when a restorative material is chosen in esthetic challenging cases.

\section{REFERENCES}

1. Pippin DJ, Mixson JM, Soldan-Els AP. Clinical evaluation of restored maxillary incisors: veneers vs. PFM crowns. $J$ Am Dent Assoc 1995;126:1523-1529.

2. Hammad IA, Stein RS. A qualitative study for the bond and color of ceramometals. Part II. J Prosthet Dent 1991;65:169179.

3. Dozic A, Kleverlaan CJ, Meegdes M, et al. The influence of porcelain layer thickness on the final shade of ceramic restorations. J Prosthet Dent 2003;90:563-570.

4. Christensen GJ. Facing the challenges of ceramic veneers. J Am Dent Assoc 2006;137:661-664.

5. Fradeani M, Redemagni M, Corrado M. Porcelain laminate veneers: 6- to 12-year clinical evaluation-a retrospective study. Int J Periodontics Restorative Dent 2005;25:9-17.

6. Kihn PW, Barnes DM. The clinical longevity of porcelain veneers: a 48-month clinical evaluation. $J$ Am Dent Assoc 1998;129:747-752.

7. Wee AG, Monaghan $P$, Johnston WM: Variation in color between intended matched shade and fabricated shade of dental porcelain. J Prosthet Dent 2002;87:657-666.

8. Seghi RR, Johnston WM, O'Brien WJ. Spectrophotometric analysis of color differences between porcelain systems. $J$ Prosthet Dent 1986;56:35-40.

9. O'Brien WJ, Kay KS, Boenke KM, et al. Sources of color variation on firing porcelain. Dent Mater 1991;7:170-173.

10. Jorgenson MW, Goodkind RJ. Spectrophotometric study of five porcelain shades relative to the dimensions of color, porcelain thickness, and repeated firings. $J$ Prosthet Dent 1979;42:96-105.

11. Barghi N. Color and glaze: effects of repeated firings. $J$ Prosthet Dent 1982;47:393-395.

12. Raptis NV, Michalakis KX, Hirayama H. Optical behavior of current ceramic systems. Int J Periodontics Restorative Dent 2006;26:31-41.

13. Okubo SR, Kanawati A, Richards MW, et al. Evaluation of visual and instrument shade matching. $J$ Prosthet Dent 1998;80:642-648.

14. Vichi A, Ferrari M, Davidson CL. Influence of ceramic and cement thickness on the masking of various types of opaque posts. J Prosthet Dent 2000;83:412-417.
15. Antonson SA, Anusavice KJ. Contrast ratio of veneering and core ceramics as a function of thickness. Int J Prosthodont 2001;14:316-320.

16. Miyagawa Y, Powers JM. Prediction of color of an esthetic restorative material. J Dent Res 1983;62:581-584.

17. Barath VS, Faber FJ, Westland S, et al. Spectrophotometric analysis of all-ceramic materials and their interaction with luting agents and different backgrounds. Adv Dent Res 2003; 17:55-60.

18. CIE. Colorimetry: official recommendations of the International Commission on Illumination. Paris: Commission Internationale de l'Ėclairage [International Commission on Illumination], 1976; CIE No. 15 (E-1.3.1).

19. Yilmaz C, Korkmaz T, Demirkoprulu H, et al. Color stability of glazed and polished dental porcelains. J Prosthodont 2008; 17:20-24

20. Uludag B, Usumez A, Sahin V, et al. The effect of ceramic thickness and number of firings on the color of ceramic systems: an in vitro study. J Prosthet Dent 2007;97:25-31.

21. Johnston WM, Kao EC. Assessment of appearance match by visual observation and clinical colorimetry. J Dent Res 1989;68:819-822.

22. Seghi RR, Johnston WM, O'Brien WJ. Performance assessment of colorimetric devices on dental porcelains. J Dent Res 1989;68:1755-1759.

23. Jarad FD, Moss BW, Youngson CC, et al. The effect of enamel porcelain thickness on color and the ability of a shade guide to prescribe chroma. Dent Mater 2007;23:454460.

24. Peixoto RT, Paulinelli VM, Sander HH, et al. Light transmission through porcelain. Dent Mater 2007;23:1363-1368.

25. Davis BK, Aquilino SA, Lund PS, et al: Colorimetric evaluation of the effect of porcelain opacity on the resultant color of porcelain veneers. Int J Prosthodont 1992;5:130-136.

26. Shokry TE, Shen C, Elhosary MM, et al. Effect of core and veneer thicknesses on the color parameters of two allceramic systems. J Prosthet Dent 2006;95:124-129.

27. Della Bona A. Characterizing ceramics and the interfacial adhesion to resin: I- the relationship of microstructure, composition, properties and fractography. J Appl Oral Sci 2005;13:1-9.

28. Denry IL. Recent advances in ceramics for dentistry. Crit Rev Oral Biol Med 1996;7:134-143.

29. Chu FCS, Chow TW, Chai J. Contrast ratios and masking ability of three types of ceramic veneers. J Prosthet Dent 2007;98:359-364

30. Spear F, Holloway J. Which all-ceramic system is optimal for anterior esthetics? J Am Dent Assoc 2008;139;19S-24S.

31. Christensen GJ. Ceramic veneers: state of the art. $J \mathrm{Am}$ Dent Assoc 1999;130:1121-1123. 
$\square$ Ceramic color varying thickness and luting agent

32. Powers JM, Dennison JB, Lepeak PJ. Parameters that affect the color of direct restorative resins. J Dent Res 1978;57:876-880.

33. International Commission on Illumination. Colorimetry: Official recommendations of the International Commission on Illumination, Publication CIE No. 15 (E-1,3.1). Paris: Bureau Central de la CIE, 1971.

34. Hunter RS, Harold RW. The measurement of appearance. 2nd ed. New York: John Wiley \& Sons, 1987. p. 162-193.

35. Johnston W. Color measurement in dentistry. J Dent 2009;37:e2-e6. 